\title{
A Dynamic Panel Data Approach for the Analysis of the Growth Impact of Highway Infrastructures on Economic Development
}

\author{
Onur Kalan1, Ilgin Gokasar² \\ ${ }^{1}$ Civil and Urban Engineering Department, New York University, NY, USA \\ ${ }^{2}$ Department of Civil Engineering, Bogazici University, Istanbul, Turkey \\ Email: ok22@nyu.edu, ilgin.gokasar@boun.edu.tr
}

How to cite this paper: Kalan, O., \& Gokasar, I. (2020). A Dynamic Panel Data Approach for the Analysis of the Growth Impact of Highway Infrastructures on Economic Development. Modern Economy, 11, 726-739.

https://doi.org/10.4236/me.2020.113053

Received: February 4, 2020

Accepted: March 23, 2020

Published: March 26, 2020

Copyright (๑) 2020 by author(s) and Scientific Research Publishing Inc. This work is licensed under the Creative Commons Attribution International License (CC BY 4.0).

http://creativecommons.org/licenses/by/4.0/

\begin{abstract}
Turkey is a developing country where the transportation sector receives a considerable economic share. Roads are the pioneer mode of transportation in Turkey and the common opinion is that increasing highway networks lead to major changes in economic development. This paper focuses on the growth impact of highway infrastructure on economic development and recommends a dynamic panel data approach which is not common in the transportation economics literature. This model is applied to local regions that are located in the eastern and northern parts of Turkey to measure the effects of highway capital stocks on Gross Domestic Product (GDP) change between 2004 and 2016. The analysis reveals that the relationship between GDP and highway capital stock is positive, and statistically significant for local regions in Turkey. It is indicated that the findings of this paper can be a guide for policy and decision-makers and implemented into different regions and locations.
\end{abstract}

\section{Keywords}

Highway Investment, Highway Capital, Economic Growth, Panel Data,

Dynamic Panel Data Model

\section{Introduction \& Background}

Transportation expansion and improvement of the existing capacities are the key determinants for the performance of the infrastructure systems. An efficient transportation system can lead to greater economic and social benefits by improving market accessibility, increasing production efficiency, providing balanced growth of regional economies, providing employment and enabling labor 
force mobility (Eberts, 2000; Litman, 2010; OECD, 2018).

Many of the previous studies have identified relationships between transportation investment and benefit or output. For this purpose, the benefits and costs of the projects or actions can be calculated using some approaches, such as life cycle cost analysis and decision-making processes (Gao et al., 2019; Kalan et al., 2019; Kalan, 2019). In macro level, the output of transportation investments can be scrutinized and some findings indicate a positive relationship between transportation investment and economic development (Aschauer, 1990; Ozbay et al., 2003; Ozbay et al., 2006; Ozbay et al., 2007). However, some studies show an insignificant and even negative relationship between transportation investments and economic growth. Possible reasons for those results include the construction of an excess of roadways, underutilized capacities of existing networks, negative spillover effects, not to achieve corresponding cost utilizations or easiness in logistics, etc. (Kalan, 2017). Therefore, the authors focus on the impact of highway capital stock increase on economic growth in local level.

The effects of transportation and highway investments on economic growth in different countries and regions are evaluated in some of the studies in the literature (Aschauer, 1990; Asomani-Boateng et al., 2015). The literature depicts a significant variationin the relationships between transportation investments and economic changes, in terms of the positive or negative impact and output elasticity values as well. Some of these existing studies find that transportation has a positive impact on economic growth output (Aschauer, 1990; Ozbay et al., 2006; Moomaw \& Williams, 1991; Garcia-Mila \& McGuire, 1992). The output elasticity results differ from high to low values such as, 0.39 - 0.56 (Aschauer, 1989), 0.33 (Munnell \& Cook, 1990), 0.25 (Moomaw \& Williams, 1991), $0.135-0.206$ (Calderón \& Servén, 2004), 0.04 (Garcia-Mila \& McGuire, 1992), 0.08 (DuffyDeno \& Eberts, 1989; Kalan, 2019). The difference of coefficients in the models stems from the differences in the definition of capital stock, estimation methods and level of analysis and the time periods of the analysis conducted. For example, once a transportation infrastructure reaches its equilibrium or saturation point, then the additional infrastructure may not be impactful as much as in the past when the transportation infrastructure has not reached a saturation level yet. However, some of the studies find light evidence for transport-led economic growth contention, such as Chandra and Thompson (2000) and Evans and Karras (1994).

It is often emphasized in the literature that transportation infrastructure investments have positive impacts on the growth of the local and national level economic indicators. However, some of the studies question this straightforward approach. Jiang et al. (2017) propose a structural equation model (SEM) to consider the bi-directional and complicated relationship among the economic growth and transportation improvements. The analysis is conducted on a panel dataset in China from 1986 to 2011 where the spillover effects are also investigated. The results show that the impacts of transportation investments are significant for the current and surrounding regions. However, the magnitude of the 
impacts on economic impact can differ once the level of consideration changes from local to national level. These differences can be stemmed from the different economic policies, transportation infrastructure service levels and spillover effects from other regions (Jiang et al., 2017). The approaches of this study and our paper's research question have similarities. Our approach questions the finding of insignificant results for road capital stock and economic growth relation in Turkey at the national level and proposes a dynamic panel data approach to investigate the local economic growth impact of regional road capital stocks. The results of our paper provide a positive and significant relationship as it is found in Jiang et al. (2017)'s study. Our dynamic panel also controls for the endogeneity impact of the bi-directional relationship between transportation capital stock and economic growth.

Li and Whitaker (2018) also have a similar research question that investigates the linkage between county-level economic impact of highway investments in the panel dataset of Texas from 1990 to 2012 by using a mixed-effects model. Their findings show that after controlling the spillover, time lag, and other random effects, the highway investments have a positive but limited effect on county jobs. Li and Whitaker (2018) argue that there can be some different reasons behind these findings, such as limitations of the impact of post-highway-era investments on economic outputs, difficulties in isolating the transportation effects from the other major processes associated with economic growth (Black, 2003; Hanson \& Giuliano, 2004; Wilson, 1986; Eberts, 1990; Li \& Whitaker, 2018).

As a fact that constructing a new road may not have a greater impact on economic growth if there is enough infrastructure stock. In this case, these can be better solutions, such as utilizing the existing infrastructural capacity, focusing on mobility management and cost-effective solutions to increase the effectiveness of the economy overall. The possible reasons for achieving insignificant or negative results are explained in detail in the following parts.

From a transportation perspective, the general problem for the decision-makers is the capital expansion or capital enhancement decisions. The important question is should money be spent on additional highways or rather on enhancing the existing systems. Constructing additional highways, additional capacity for terminals by using traditional technology is included in the expansion. Enhancement includes increasing the efficiency of the existing transportation system, for example by using congestion pricing, GPS systems, intelligent transportation systems (Eberts, 2000).

It is in general accepted that highway infrastructure expansions have a positive impact on economic output as also supported by some performed studies mentioned above. However, in reality, the expansion of infrastructure has a wide range of effects. For instance, building the first roadway can create a major increase in the productivity of the economy in a specified location. But, constructing the second highway may decrease the marginal benefit of productivity. Due to the congestion, building a new highway lane may decrease the costs caused by 
congestion, however, different congestion management strategies can lead to more cost-effective results (Litman, 2010).

Traffic congestion is an important factor in terms of productivity. Hymel (2009) mentions the traffic congestion and employment growth relationship in US metropolitan areas. The results point out that congestion leads to a decrease in employment growth. This is especially observed in a highly congested location for long-term periods. Additionally, this study indicates the finding that a $10 \%$ increase in congestion in highly congested cities leads to a decrease in employment growth by 4\%, for example, in Los Angeles (Hymel, 2009; Jiwattanakulpaisarn et al., 2009; Litman, 2010). This study shows that congestion has an essential impact on local economic growth.

In the congestion perspective, Litman's (2010) report claims that highway expansion supporters assume that traffic congestion leads to a decrease in productivity and expanding roadway also decreases congestion costs and, additionally, the alternative strategies to decrease the congestion are not sufficient to remedy its costs. However, Litman (2010) mentions in the same report that highway expansion tends to decrease the congestion in the long period, but its benefits are captured generally by the consumer costs. Therefore, a significant improvement in net productivity cannot be observed. However, mobility management supports to generate an overall improvement in net productivity with the help of an increase in overall efficiency (Litman, 2010).

Highway expansion may lead to another result which is economic transfer rather than an overall increase in economic outputs (Baird, 2005; Chalermpong, 2004; Litman, 2010). Weiss (1999), Horst and Moore (2003) find that suburban or rural areas with good accessibility achieve more industrial diversification, employment growth, and poverty alleviation (Horst \& Moore, 2003; Weiss, 1999). However, this type of economic sprawl by roadway expansions may be harmful to the local economies. For example, Nelson and Moody (2000) indicate that economic retail and services per person are reduced by the increase in the beltways. These findings lead us to the result that additional beltways may cause deconcentration of people and economic activities which can reduce the agglomeration efficiency of industries (Litman, 2010; Nelson \& Moody, 2000).

SACTRA (1999) and O'Fallon (2003)'s conclusions below summarize the possible reasons not to achieve expected positive results by expanding the existing highway infrastructure stock (O’Fallon, 2003; SACTRA, 1999a, 1999b):

1) Transport investments may lead to wide impacts. These can be negative or positive. For instance, an increase in the number of residential trips for shopping and services may decrease the economic activities in this location.

2) Improvement in the existing capacity may be more productive than the expansion of the existing stocks. Demand management would be a better alternative than expanding the existing stocks.

3) The reliability of the infrastructure stock is an important factor for international trade. Poor quality and inefficient infrastructure may lead to the reluctance of the firms for investing capital in those locations. 
4) Surplus of the existing infrastructure may cause a negative impact because of the unnecessary usage of scarce resources.

5) Decisions given by political influences (i.e. lobbying, coalition agreements) may lead to distortions in infrastructure improvements.

In the lights of the information above, the next questions become vital before deciding the strategies (Litman, 2010).

- Can the work increase overall productivity?

- Is the work the best way to support local development?

- Is the work the best way to improve access?

- Does the work provide overall economic gains or just transferring them?

- Do the benefits correspond to subsidies?

In terms of the effect of highways on growth, the mobility and economic productivity relationship are an indicator of the efficiency of the transportation modes. A flexible relationship between mobility and economic productivity shows that economies are responsive and creative.

The authors focus on the questions (1) and (4) above and decide to perform an econometric analysis that considers local regions of Turkey and clarify the impact of road expansions on economic growth specific locations.

The objective of this paper is to recommend a dynamic panel data approach applied to local regions that are located in the eastern and northern parts of Turkey to understand the impact of road infrastructure increase in local economic growth. Due to the aforementioned reasons, achieving positive and significant results is not possible at the national level (Kalan, 2017). Therefore, the authors select Eastern Anatolia, Southeastern Anatolia, Central Anatolia, and the Black Sea regions dataset between 2004 and 2016 years to perform an econometric analysis with a regional economic growth perspective. The reasons for choosing these regions are listed as: 1) the percent change in the highway mileages of the selected regions between 2004 and 2016 years are higher in percentage than the other parts of Turkey which leads to observe the changes in the output easier; 2) the overall GDP and the urbanization levels of the selected regions are relatively lower than the other regions which supports ideas provided in the mentioned above where the expansion in highway capital stock does not impact the local economic growth significantly when the existing physical infrastructure is at a sufficient level.

In addition to the motives above, in the literature, there are numerous studies that measure the growth impact of transportation and highway capital on economic development. However, there is not a study exist in the literature which analyzes the impact of highway capital stock on economic development in Turkey, especially in local regions. Therefore, this paper aims to address the measurement of the relationship between economic growth and highway infrastructure development at local levels in Turkey. One of the most important contributions of this paper is performing our research with the dynamic panel data methodology in the transportation economics literature, where the instrumental variables approach may not always be easy to apply in terms of finding appro- 
priate instruments for the solution (i.e., suffering from an over-identification problem; see (Chatman et al., 2012)). The dynamic panel data model allows researchers to use both the differenced dependent and independent variables as instruments. Another contribution of our paper is calculating the road capital stocks for Turkey atregional and provincial levels for the first time in the literature. The main added value of our paper is showing that the increase in road infrastructure in Turkey has significant and positive impacts at local regional levels.

The rest of the paper is structured as follows: The Study Area and the Data, Production Function-Based Model, Proposed Model Specification, Results and Discussion, Conclusion and Future Studies.

\section{The Study Area and the Data}

The study area includes Eastern Anatolia, Southeastern Anatolia, Central Anatolia, and the Black Sea regions which are located in the eastern and northern parts of Turkey. The first reason to choose these locations is the change in the highway mileages is higher in percentage than the other parts of Turkey. The second reason is that the selected regions are more sensitive to the change in highway capital stock than the western part of Turkey is in terms of GDP growth. These regions are represented in the models with Regional Level-2 sub-regions given in the Turkish Statistical Institute (TURKSTAT) which are formed by grouping a number of provinces in these selected sub-regions according to Nomenclature of Territorial Units of Statistics (NUTS) classification ("Turkish Statistical Institute", 2018).

The dataset employed consists of output (i.e., GDP), labor and highway capital for these four regions between 2004 and 2016. All monetary variables are measured in real Turkish Liras (TL) and were converted to the year $1998 \mathrm{TL}$. Employment data are also obtained from the TURKSTAT in Regional Level-2 sub-regions ("Turkish Statistical Institute", 2018).

The road capital stock does not exist in the econometrics literature for Turkey. Therefore, the authors calculate the road capital stock values using the expense information of the General Directorate of Highways (KGM) available in the open-source ("Allocations and Expenditures of General Directorate of Highways by Years in Current Prices", 2018; Kalan, 2017). The highway capital stock values are calculated using the Perpetual Inventory Method (PIM). Highway capital stocks were computed using the following perpetual inventory accounting formula:

$$
K_{t}=K_{t-1}(1-\delta)+I_{t}
$$

where " $K$ " is capital stock, " $P$ " is an investment, " $\delta$ " is depreciation rate.

In compliance with the Perpetual Inventory Method, the highway capital stocks for each year are calculated for each corresponding year and Regional Level-2 sub-region. The found highway capital stock values are disaggregated into Regional Level-2 sub-regions by dividing the overall highway capital stocks 
into the Regional Level-2 highway mileage percentages for each year between 2004 and 2016. Due to the lack of disaggregated data at the region and Regional Level-2 sub-region level, this approach is implemented in this paper.

\section{Production Function-Based Model}

There are many studies about the production function based models. The Cobb-Douglas method is one of the most common methods in econometrical analyses based on capital stock theory. The Cobb-Douglas structure is (Coma \& Douglas, 1928):

$$
Y_{t}=(\mathrm{MFP})_{t} L_{t}^{\alpha} P_{t}^{\beta} G_{t}^{\gamma},
$$

where $Y$ is the aggregate output (for example GDP), MFP is a measure of multi-factor productivity (for example technology), and $L, P$, and $G$ are, respectively, labor, private and public capital stocks.

Typically, if the production form is linearized, the natural logarithm of both sides can be taken as:

$$
\ln Y_{t}=\ln (\mathrm{MFP})_{t}+\alpha \ln L_{t}+\beta \ln P_{t}+\gamma \ln G_{t},
$$

where $\alpha, \beta, \gamma$ are the coefficients of the log-transform regressions.

\section{Proposed Model Specification}

In this paper, a panel data approach is used. In panel data analyses, a fixed-effect model can be applied to avoid the unobserved factors constant over time. In this paper, a panel data approach is used. The general aim of using panel data is to search for unobserved factors that impact the output. There are two types of those factors: constant or varying over time. Let $i$ represents the location and $t$ the time, a single regressor observed model is (Wooldridge, 2003):

$$
y_{i t}=\beta_{0}+\delta d 2_{t}+\beta_{1} x_{i t}+\alpha_{i}+u_{i t}, t=1,2, \cdots
$$

The variable $d_{t}$ is a dummy variable that equals zero when $t=1$ and one when $t=2$. The dummy variable does not change between locations. Therefore, the intercept for $t=1$ is $\beta_{0}$, and the intercept for $t=2$ is $\beta_{0}+\delta_{0}$. In independently pooled cross-sections, allowing the intercept is allowed to change over time (Wooldridge, 2003).

The $a_{i}$ variable includes all time-constant and unobserved factors over $y_{i t} a_{i}$ is called an unobserved effect and does not change over time. The error $u_{i t}$ is generally named as time-varying error or idiosyncratic error. It displays the unobserved effects that change over time (Wooldridge, 2003). Brief definitions of the variables are provided in Table 1.

If the model (1) considered, a two-year period can be thought of in two ways: just pooling two years and using OLS, and assuming that $a_{i}$ is uncorrelated with $\boldsymbol{X}_{i t}$ (Wooldridge, 2003):

$$
y_{i t}=\beta_{0}+\delta d 2_{t}+\beta_{1} x_{i t}+v_{i t}
$$


Table 1. Definitions of the variables (Wooldridge, 2003).

\begin{tabular}{cc}
\hline Symbols & Definitions \\
\hline$\beta$ & Intercept \\
$\delta$ & Change in intercept \\
$d 2$ & Dummy variable \\
$x_{i t}$ & Regressor \\
$u_{i t}$ & Time-varying error \\
$\alpha_{i t}$ & Fixed effect \\
$i$ & Location index \\
$t$ & Time index \\
\hline
\end{tabular}

$$
v_{i t}=\alpha_{i}+u_{i t}
$$

But, if $a_{i}$ and $x_{i t}$ are correlated, OLS is biased and therefore the results are biased. It is called heterogeneity bias, resulting from omitting a time-constant variable. According to our panel dataset and panel data methodology, the existence of the time-constant variable is tested with the Hausman-Taylor methodology. The results showed that this variable exists in the model (Wooldridge, 2003).

To eliminate this bias, some methodologies can be used. One is taking the difference of the model with respect to the previous year's model, and therefore the time-constant effect can be eliminated. An alternative and a common way to eliminate this unobserved time-constant effect, $a_{i}$ is a fixed effect estimation. The fixed-effect estimation for one explanatory variable (Wooldridge, 2003):

$$
y_{i t}=\beta_{1} x_{i t}+\alpha_{i}+u_{i t}, t=1,2, \cdots, T
$$

For each $i$, taking averages over time gives:

$$
y_{i}=\beta_{i} \bar{x}_{i}+\bar{\alpha}_{i}+\bar{u}_{i}
$$

when the Equation (11) is subtracted from Equation (10);

$$
y_{i t}-\bar{y}_{i}=\beta_{i}\left(x_{i t}-\bar{x}_{i}\right)+u_{i t}-\bar{u}_{i}, t=1,2, \cdots, T
$$

In other terms;

$$
\dot{y}_{i t}=\beta_{1} \dot{x}_{i t}+\dot{u}_{i t}, t=1,2, \cdots, T
$$

where $\dot{y}_{i t}=y_{i t}-\bar{y}_{i}$ is the demeaned data on $y$. This method is called within a transformation or a fixed effect approach. A pooled OLS estimator that is based on time-demeaned variables is called a fixed effect estimator or within estimator (Wooldridge, 2003).

One of the most common problems observed in this type of econometric analysis model is the endogeneity problem. An endogeneity problem is the relation of one or more independent variables with the error term in the model. This type of problem can generally occur for different reasons, such as measurement error, autoregression with autocorrelated errors, simultaneous causality, omitted variables and so on. Additionally, cross-sectional dependency can be a strong reason for this endogeneity problem. 
To overcome a potential endogeneity problem, there are also some panel data methodologies such as the simultaneous equations approach, using instrumental variables, etc. In O. Kalan (2019) study, a dynamic linear panel data methodology is used which is called Arellano-Bover/Blundell-Bond linear dynamic panel-data estimation to measure the impact of highway stock on local economic growth in New York and New Jersey region. In this paper, this methodology is modified in terms of independent variable lags and applied for northern and western regions of Turkey. In the following parts, this methodology is explained in detail (Arellano \& Bond, 1991; Arellano \& Bover, 1995; Blundell \& Bond, 1998).

A dynamic panel data model can be expressed as:

$$
y_{i t}=\sum_{j=2}^{p} \alpha_{j} y_{i, t-j}+x_{i, t} \beta_{1}+w_{i, t} \beta_{2}+v_{i}+\varepsilon_{i, t}
$$

where $i=1, \cdots, N ; t=1, \cdots, T_{i}$ and

$a_{j}$ and $p$ are the parameters to be estimated;

$\mathrm{x}_{\mathrm{it}}$ is a $1 \times k_{1}$ vector of strictly exogenous covariates;

$\beta_{1}$ is a $k_{1} \times 1$ vector of parameters to be estimated;

$W_{i t}$ is a $1 \times k_{2}$ vector of predetermined or endogenous covariates;

$\beta_{2}$ is a $k_{2} \times 1$ vector of parameters to be estimated;

$v_{i}$ are the panel-level effects (which may be correlated with the covariates); and

$\varepsilon_{i t}$ are i.i.d. over the whole sample with variance $\sigma 2 \mathcal{\varepsilon}$.

The $v_{i}$ and the $\varepsilon_{i t}$ are assumed to be independent for each $i$ overall $t$. In this model, the fundamental problems are:

Due to $y_{i t}$ is a function of $v_{p}$ so is $y_{i, t-1}$, Ordinary Least Square is biased and inconsistent even if the $e_{i t}$ are not serially correlated.

Since the within transformation clears the mi, but we get problems because the correlation with $y_{i, t-1}$ and $\mathrm{e}_{\text {avgii }}$ (this mean contains $e_{i, t-1}$ ). Therefore, Fixed Effect is biased but still consistent for $T \rightarrow \infty$.

Blundell and Bond (1998) show that the lagged-level instruments in the Arellano-Bond estimator become weak as the autoregressive process becomes too persistent or the ratio of the variance of the panel-level effects $v_{i}$ to the variance of the idiosyncratic error $\varepsilon_{i t}$ becomes too large. Building on the work of Arellano and Bover (1995) and Blundell and Bond (1998) proposed a system estimator that uses moment conditions in which lagged differences are used as instruments for the level equation in addition to the moment conditions of lagged levels as instruments for the differenced equation. The additional moment conditions are valid only if the initial condition $E\left[v_{i} \Delta y_{i 2}\right]=0$ holds for all $i$ (Stata Manual, 2018).

Therefore, our model becomes:

$$
\begin{aligned}
\ln \left(\operatorname{gdp}_{i, t}\right)-\ln \left(\text { labor }_{i, t}\right)= & \alpha_{0}+\alpha_{1}\left[\ln \left(\operatorname{gdp}_{i, t-1}\right)-\ln \left(\text { labor }_{i, t-1}\right)\right] \\
& +\alpha_{2}\left[\ln \left(\operatorname{hgstock}_{i, t}\right)-\ln \left(\text { labor }_{i, t}\right)\right]+\varepsilon_{i, t},
\end{aligned}
$$


where "gdp" is the Gross Domestic Product, "hgstock" is the highway capital stock value in 1998 TL. "Labor" is the employment data (number of total jobs), $i$ is Regional Level-2 sub-region and $t$ is the time index.

As mentioned in the Study Area and the Data section, the highway stock value is evaluated using the Perpetual Inventory Method. In the following section, the model results are represented and the year 2017 GCP estimations are compared with the real data for the robustness of the new models.

\section{Results and Discussion}

The dynamic panel data analysis is performed using the log-transform model in Equation (5). The results are provided in Table 2.

The results provide significant values within the $10 \%$ confidence interval. Highway capital stock per labor coefficient estimation is close to between 0.05 which is consistent with the findings in O. Kalan (2019).

The model results are used to forecast the year 2017 GDP values of the subgroups used in the dataset. The errors are estimated. The average error in the overall dataset is found at $0.30 \%$. For example, our model estimates the GDP value of Samsun, Tokat, Corum, Amasya subgroup of Black Sea region as 3,943,543,120 TL in $1998 \mathrm{TL}$ prices. The actual GDP provided by TURKSTAT for this subgroup is 3,865,048,440 TL in 1998 TL prices ("Turkish Statistical Institute", 2018). This means the error in the recommended model predictions for this Regional Level-2 sub-region is only $2.03 \%$. When the same analysis is carried out for all the Regional Level-2 sub-regions, an average error in the overall dataset is found as $0.30 \%$. These findings demonstrate the robustness of the recommended model.

\section{Conclusion \& Future Studies}

In many studies, the transportation infrastructure and changes in the economic indicators are examined by using the appropriate data to represent the variables. One of the important variables commonly used is the capital stock values of the transportation infrastructure. In this paper, highway capital stock and its impact on economic growth are scrutinized. Therefore, the authors decide to perform an econometric analysis that considers local regions of Turkey and clarify the impact of road expansions on economic growth in specific locations.

The results provide significant values within the $10 \%$ confidence interval. Highway capital stock per labor coefficient estimation is close to between 0.05

Table 2. Results of the regional econometric model.

\begin{tabular}{cccccccc}
\hline $\begin{array}{c}\text { Results of the } \\
\text { Econometric Model }\end{array}$ & Coef. & Robust Std. Err. & $\boldsymbol{z}$ & $\boldsymbol{P}>|\boldsymbol{z}|$ & \multicolumn{2}{c}{ [95\% Conf. Interval] } \\
\hline $\operatorname{lngdp}_{t-1}$ & 0.7736759 & 0.0922681 & 8.39 & 0.000 & 0.5928337 & 0.9545181 \\
$\operatorname{lnnoad}_{t}$ & 0.0590524 & 0.0348260 & 1.70 & 0.090 & -0.0092054 & 0.1273102 \\
Constant & 1.5300870 & 0.5797300 & 2.64 & 0.008 & 0.3938369 & 2.6663370 \\
\hline
\end{tabular}


which is consistent with the findings in O. Kalan (2019). Additionally, the model results are used to forecast the year 2017 GDP values of the subgroups used in the dataset. The errors are estimated. The average error in the overall dataset is found at $0.30 \%$. This explains that the questions given in the previous paragraph are important and suggested by the authors to bring up to the policymakers and decision-makers' attention.

Results achieved in this study can be a guide for implementing policies and during the decision making phase for the allocation of the investment amounts in highway infrastructure and other alternatives in the transportation sector as well. Furthermore, the analyses and recommendations can be taken as a reference by policy and decision-makers to give a decision for allocating the resources on the sectoral level of public investments. At the preparation phase of the development plans, especially in developing countries, this substantial evidence can lead to the allocation of public funds more accurately. Therefore, scarce resources can be used more efficiently.

For future studies, transportation infrastructure and economic growth relation and impacts on economic achievements can be researched for different regions in the local base. In emerging countries which have similar properties, highway or any other transportation enhancement options can be investigated by taking into consideration the mentioned efficiency problems. Rail transport, maritime transport, airline transport systems also can be considered in different types of econometric models for emerging countries to understand the other transportation modes' impacts on economic growth.

\section{Acknowledgements}

The authors thank the editor and peer reviewers for their comments and feedback.

\section{Conflicts of Interest}

The authors declare no conflicts of interest regarding the publication of this paper.

\section{References}

Allocations and Expenditures of General Directorate of Highways by Years (In Current Prices) (2018).

http://www.kgm.gov.tr/SiteCollectionDocuments/KGMdocuments/Eng/Statistics/Budg etAllocations-ExpendituresAndRevenues/AllocationsAndExpendituresOfGeneralDirec torateOfHighwaysByYearsING.pdf

Arellano, M., \& Bond, S. (1991). Some Tests of Specification for Panel Data: Monte Carlo Evidence and an Application to Employment Equations. The Review of Economic Studies, 58, 277-297. https://doi.org/10.2307/2297968

Arellano, M., \& Bover, O. (1995). Another Look at the Instrumental Variable Estimation of Error-Components Models. Journal of Econometrics, 68, 29-51. https://doi.org/10.1016/0304-4076(94)01642-D

Aschauer, D. A. (1989). Is Public Expenditure Productive? Journal of Monetary Econom- 
ics, 23, 177-200. https://doi.org/10.1016/0304-3932(89)90047-0

Aschauer, D. A. (1990). Highway Capacity and Economic Growth. Economic Perspectives, 14, 4-24.

Asomani-Boateng, R., Fricano, R. J., \& Adarkwa, F. (2015). Assessing the Socio-Economic Impacts of Rural Road Improvements in Ghana: A Case Study of Transport Sector Program Support (II). Case Studies on Transport Policy, 3, 355-366. https://doi.org/10.1016/j.cstp.2015.04.006

Baird, B. A. (2005). Public Infrastructure and Economic Productivity: A Transportation-Focused Review. Transportation Research Record, 1932, 54-60. https://doi.org/10.1177/0361198105193200107

Black, W. R. (2003). Transportation: A Geographical Analysis. New York: Guilford Press.

Blundell, R., \& Bond, S. (1998). Initial Conditions and Moment Restrictions in Dynamic Panel Data Models. Journal of Econometrics, 87, 115-143. https://doi.org/10.1016/S0304-4076(98)00009-8

Calderón, C., \& Servén, L. (2004). The Effects of Infrastructure Development on Growth and Income Distribution. Washington DC: The World Bank. https://doi.org/10.1596/1813-9450-3400

Chalermpong, S. (2004). Empirical Study of Economic Spillovers of Interstate 105 in Los Angeles County. Transportation Research Record, 1864, 94-102. https://doi.org/10.3141/1864-13

Chandra, A., \& Thompson, E. (2000). Does Public Infrastructure Affect Economic Activity? Evidence from the Rural Interstate Highway System. Regional Science and Urban Economics, 30, 457-490. https://doi.org/10.1016/S0166-0462(00)00040-5

Chatman, D. G., Noland, R. B., Tulach, N. K., Grady, B. P., Ozbay, K., Rognlien, L., Bilton, P. et al. (2012). Methodology for Determining the Economic Development Impacts of Transit Projects. https://doi.org/10.17226/22765

Coma, C. W., \& Douglas, P. H. (1928). A Theory of Production. In Proceedings of the Fortieth Annual Meeting of the American Economic Association (pp.139-165). The American Economic Review.

Duffy-Deno, K. T., \& Eberts, R. W. (1989). Public Infrastructure and Regional Economic Development: A Simultaneous Equations Approach. Cleveland, OH: Federal Reserve Bank of Cleveland, Research Department.

Eberts, R. (2000). Understanding the Impact of Transportation on Economic Development. Transportation in the New Millennium.

Eberts, R. W. (1990). Public Infrastructure and Regional Economic Development. Economic Review, 26, 15-27.

Evans, P., \& Karras, G. (1994). Are Government Activities Productive? Evidence from a Panel of US States. The Review of Economics and Statistics, 76, 1-11. https://doi.org/10.2307/2109821

Gao, J., Ozbay, K., Nassif, H., \& Kalan, O. (2019). Stochastic Multi-Objective Optimization-Based Life Cycle Cost Analysis for New Construction Materials and Technologies. Transportation Research Record: Journal of the Transportation Research Board, 2673, 466-479. https://doi.org/10.1177/0361198119853578

Garcia-Mila, T., \& McGuire, T. J. (1992). The Contribution of Publicly Provided Inputs to States' Economies. Regional Science and Urban Economics, 22, 229-241. https://doi.org/10.1016/0166-0462(92)90013-Q

Hanson, S., \& Giuliano, G. (2004). The Geography of Urban Transportation. New York: 
Guilford Press.

Horst, T., \& Moore, A. (2003). Industrial Diversity, Economic Development, and Highway Investment in Louisiana. Transportation Research Record, 1839, 136-141. https://doi.org/10.3141/1839-15

Hymel, K. (2009). Does Traffic Congestion Reduce Employment Growth? Journal of Urban Economics, 65, 127-135. https://doi.org/10.1016/j.jue.2008.11.002

Jiang, X., He, X., Zhang, L., Qin, H., \& Shao, F. (2017). Multimodal Transportation Infrastructure Investment and Regional Economic Development: A Structural Equation Modeling Empirical Analysis in China from 1986 to 2011. Transport Policy, 54, 43-52. https://doi.org/10.1016/j.tranpol.2016.11.004

Jiwattanakulpaisarn, P., Noland, R. B., \& Graham, D. J. (2009). Marginal Productivity of Expanding Highway Capacity.

Kalan, O. (2017). The Relationship between Economic Growth and Road Infrastructure: Evidence from Turkey. İstanbul: Bogaziçi University.

Kalan, O. (2019). Application of Region Specific Depreciation Formulas in Highway Capital Stocks: Evidence from New York and New Jersey. In Transportation Research Board's 98th Annual Meeting. Washington D.C.: Transportion Research Board.

Kalan, O., Abdullah, K., \& Ozbay, K. (2019). Is Additive Utility Function Always a Sufficient Method in the Project Prioritization Process? A Bridge Management Perspective. Transportation Research Record: Journal of the Transportation Research Board, 2673, 284-294. https://doi.org/10.1177/0361198119846466

Li, J., \& Whitaker, E. (2018). The Impact of Governmental Highway Investments on Local Economic Outcome in the Post-Highway Era. Transportation Research Part A: Policy and Practice, 113, 410-420. https://doi.org/10.1016/j.tra.2018.04.023

Litman, T. (2010). Evaluating Transportation Economic Development Impacts.

Moomaw, R. L., \& Williams, M. (1991). Total Factor Productivity Growth in Manufacturing Further Evidence from the States. Journal of Regional Science, 31, 17-34. https://doi.org/10.1111/j.1467-9787.1991.tb00128.x

Munnell, A. H., \& Cook, L. M. (1990). How Does Public Infrastructure Affect Regional Economic Performance? New England Economic Review, 11-33.

Nelson, A. C., \& Moody, M. (2000). Effect of Beltways on Metropolitan Economic Activity. Journal of Urban Planning and Development, 126, 189-196. https://doi.org/10.1061/(ASCE)0733-9488(2000)126:4(189)

O'Fallon, C. (2003). Linkages between Infrastructure and Economic Growth. Ministry of Economic Development, Government of New Zealand.

OECD (2018). OECD Data-Infrastructure Investment. https://data.oecd.org/transport/infrastructure-investment.htm

Ozbay, K., Ozmen-Ertekin, D., \& Berechman, J. (2003). Empirical Analysis of Relationship between Accessibility and Economic Development. Journal of Urban Planning and Development, 129, 97-119.

https://doi.org/10.1061/(ASCE)0733-9488(2003)129:2(97)

Ozbay, K., Ozmen-Ertekin, D., \& Berechman, J. (2007). Contribution of Transportation Investments to County Output. Transport Policy, 14, 317-329.

https://doi.org/10.1016/j.tranpol.2007.03.004

Ozbay, K., Ozmen, D., \& Berechman, J. (2006). Modeling and Analysis of the Link between Accessibility and Employment Growth. Journal of Transportation Engineering, 132, 385-393. https://doi.org/10.1061/(ASCE)0733-947X(2006)132:5(385) 
SACTRA (1999a). A Framework for Assessing Studies of the Impact of Transport Infrastructure Projects on Economic Activity. Standing Advisory Committee on Trunk Road Assessment.

http://www.dft.gov.uk/stellent/groups/dft/transstrat/documents/page/dft-transstrat-50 4940.pdf

SACTRA (1999b). Transport Investment, Transport Intensity and Economic Growth. Standing Advisory Committee on Trunk Road Assessment.

http://www.dft.gov.uk/pgr/economics/sactra

Stata_Manual (2018). xtdpdsys-Arellano-Bover/Blundell-Bond Linear Dynamic Panel-Data Estimation. https://www.stata.com/manuals13/xtxtdpdsys.pdf

Turkish Statistical Institute (2018). http://www.turkstat.gov.tr/Start.do

Weiss, M. (1999). Economic Growth from Transportation Improvements: Does It or Doesn't It. In Sixth National Conference on Transportation Planning for Small and Medium Sized Communities. Transportation Research Board, Federal Highway Administration, Federal Transit Authority, Institute of Transportation Engineers, Oregon Department of Transportation and Idaho Transportation Department.

Wilson, G. W. (1986). Economic Analysis of Transportation: A Twenty-Five Year Survey. Transportation Journal, 26, 33-44.

Wooldridge, J. M. (2003). Introductory Econometrics: A Modern Approach. 